\title{
The Influence of Uniform in Establishing Unity, Hierarchy, and Conformity at Thai Universities
}

\author{
Sasanun Bunyawanich ${ }^{1}$, Maria-Liisa Järvelä ${ }^{2}$, Abdul Ghaffar ${ }^{3}$ \\ ${ }^{1}$ Faculty of Education, Suan Dusit University, Thailand \\ ${ }^{2}$ Faculty of Education, University of Oulu, Finland \\ ${ }^{3}$ College of Public Health Sciences, Chulalongkorn University, Thailand \\ Correspondence: Sasanun Bunyawanich, Faculty of Education, Suan Dusit University, 295 Nakorn Rachasima Rd., Dusit, \\ Bangkok 10300, Thailand.
}

Received: April 2, 2018

Accepted: May 3, $2018 \quad$ Online Published: May 7, 2018

doi:10.11114/jets.v6i7.3151

URL: https://doi.org/10.11114/jets.v6i7.3151

\begin{abstract}
In most countries, wearing uniform in the university level is a rare practice. Interestingly, Thailand is one of a very few countries requiring the undergraduate students to wear the student uniform to attend class on daily basis. The university uniform has been seen to represent the ideas of politeness, honor, unity, and uniqueness of Thai culture. Hence, the practice of wearing the uniform is anchored on Thainess, the core of which is founded on kingship, religion, and nation creating a sense of shared identity among the Thai people. This research investigated (1) students' experiences of wearing the uniform concerning power relation among Thai university students inside and outside their universities, and (2) students' experiences regarding their personal development and how the university dress code affects them. This is the qualitative study of which theoretical frameworks are grounded on concepts of habitus and cultural representation by Pierre Bourdieu and Stuart Hall. As the study focuses on students' experiences, the phenomenological approach was applied. A total of eight interviews were carried out with students in Kasetsart University (Kamphaeng Saen Campus) and Nakorn Pathom Rajabhat University by purposive sampling. Data analysis was conducted with thematic content analysis. The research findings reveal experiences of the strict dress code indicating that the uniform engages with symbolic communication and hierarchical empowerment. Wearing the uniform keeps up the illusion of uniformity while exerting suppression of individuality. Further the strict dress code creates problematic gender issues but does not promote students' life goals.
\end{abstract}

Keywords: uniform, university students, Thailand, phenomenology, habitus

\section{Introduction}

Uniform is defined by Joseph and Alex (1972) as a costume identifying similar appearance, distinctiveness, or uniformity of a group. They viewed that uniform is not only attire that an individual wears, but also symbolizes membership of a group, while creating exclusion and otherness to people outside the group. Meadmore and Symes (1997) stated that the uniform could also reflect two-layer relationship between teachers and students. The uniform was viewed to contain a sense of superiority of teachers and inferiority of the students. Dress code is influential in shaping characteristics of students. Raby (2005) concluded that dress code basically creates passive characteristics and obedience to authority. On the contrary, in the school level, DeMitchell, Fossey, and Cobb (2000) mentioned that dress code receives a widespread support from principals. In their opinions, the dress code is likely to improve student's behavior and prepare them for work in real life. Amid a large number of research on student dress code and uniform in compulsory education, this study explores the influence of prevalent undergraduate uniform in Thailand.

\subsection{Student Uniform, Thainess, and Hierarchy in Thailand's Context}

Chulalongkorn University's website (n.d.) stated that the uniform of undergraduate student was initiated in the reign of King Rama the V for the students in the institution. Sooksai (2013) remarked that the undergraduate students have been required to wear the uniform because it was viewed as 1) polite and appropriate dress, 2) representing the honor of university, 3) maintaining grace, uniqueness and value of Thai culture, 4) demonstrating unity, and 5) preventing sexual abuse in the university. 
According to Liamputtong (2014), the undergraduate uniform has been intricately linked to Thainess. Thainess was introduced by King Rama $\mathrm{V}$ to create the state homogeneity for the benefits of political elites in Bangkok in response to colonial threatening. Sattayanurak (2008) mentioned that subsequently, King Rama VI developed a concept of "Thai nation" which meant the nation of Thai people who loyally adopted Thainess for their social practices laid upon triangulation pillars of nation, religion, and kingship. Bunyavejchewin (2010) stated that the real function of Thainess is an effective political tool to justify and sustain power holders and social structure. Unity or kwamsamakki was mentioned as extremely significant to Thai dominant social class because they viewed that the unity leads to stability through demanding a similar set of thinking, belief in royal nationalism, and top-down benefits. Renard (2006) informed that Thai education system has played an important role in cultivating Thai nationalistic conservativeness in a top-down approach to the students regardless of their background.

Despite the western influences and values, Thai universities strongly emphasize preservation of Thai cultures (Bovornsiri \& Fry, 1991; Rhein, 2016). Thai universities are organized in hierarchies which imitate Thai social structure (Mezey, 1975). Fakjamroon (2005) viewed that obedience to the seniority and authority is a positive personal trait of university students in Thai society; this was supported by the fact that all of Thai universities hold Wai Kru ceremony annually to pay homage to the teachers. Wai Kru is important to Thai culture in signifying that the students are aware of boonkoon (goodness or usefulness) of teachers (Kitkerdsaeng, 2011). Grubbs (2012) found that apart from the teachers, the students need to show respect to the senior students because of their seniority. The importance of respect was demonstrated through the faculty initiations that consist of senior students yelling at first-year students and telling them to do activities unrelated to their study. The activities were mentioned that they have been held purposefully by the seniors as the way of promoting unity, hierarchy, and conformity among the first-year students. Nainapat (2016) also provided the similar view by mentioning that during the initiation activities, the senior students always emphasize about wearing proper university uniform on campus and paying respect for lecturers and senior students respectively.

\subsection{Aim and Research Questions}

In Thailand's context where uniforms are mandatory at university level for the undergraduate, this study intends to explore: (1) the attribution of uniform as a symbol that can shape and distribute power to different groups of social actors grounded on cultural representation in university and general circumstance, and (2) the consequences of wearing university uniform and how students' personalities are shaped by the uniform in Thailand's context. The study aims to understand how the uniform affects the power relations inside and outside the university, and how the uniform contributes to personal development among the undergraduate.

\section{Theory}

Well knowing that the applied theories have been constructed by Westerners, they are being applied precisely because, after careful consideration, they are found well suited to the current research intention of examining the effects of certain cultural practices i.e. the strict rules of wearing the uniforms in Thai universities. The theoretical frameworks are important in underpinning data interpretation.

\subsection{Bourdieu's Theory of Practice}

Power is related to existing structure, social action, and multiple factors of social arrangements grounded on habitus, capital, and field (as cited in Navarro, 2006). Walther (2014) stated that habitus is the central concept of Bourdieu's grand social theory, and habitus is a product of social conditionings and a history, not naturally occurred or merely personal behaviors. Bourdieu (1984) pointed out that habitus drives us to act unconsciously to conform to our social position in the field. He highlighted that dominant class in the social field exerts strong influence on rule setting and puts efforts in continuation of the rules.

Anheier, Gerhards, and Romo (1995) clarified that capital is the resources of social class which engenders power hierarchies. The concepts of capital were interpreted beyond the financial notions in economics. According to their view, Bourdieu's capitals have been broadly divided into four types i.e. economic capital, cultural capital, social capital, and symbolic capital. Economic capital refers to all forms of valued resources, and can be convertible directly into money and claimed for property rights (Anheier, Gerhards, \& Romo, 1995; Navarro, 2006; Walther, 2014). Cultural capital includes long-standing dispositions and habits shaped by the process of socialization, and accumulation of valued cultural objects (Anheier, Gerhards, \& Romo, 1995). Social capital enables social reproduction anchored in two components, that is, group membership and social networks (Sablan \& Tierney, 2014). Siisiäinen (2003) inferred that symbolic capital is the symbolic recognition of differences among groups or classes. The symbolic capital was viewed the most effective when it becomes prevalent in every day's life. The authority was viewed as the powerful unit in determining symbolic capital and therefore can sustain its power.

Bourdieu (1984) mentioned that field is a social arena that actors struggle over legitimate power by improving their 
social positions, aiming to sustain or transform the existing balance of force. He also elaborated that a society has many social fields dominated by different groups of actors; for instance, the university field is dominated by the intellectuals while the political field is led by politicians. Therefore, the university is not a value-free space, but rather filled with a particular cultural value.

\subsection{Cultural Representation}

According to Hall (1997), culture is about shared meanings that deposit values and meanings of a society. Cultures were viewed as a set of abstract things which are turned into practices if being considered make-sense. It can be said that all social practices 'work like languages'; this is not because the social practices are used for written or spoken, but rather they all use some elements to stand for or represent what people want to say, to express, or communicate a thought, concept, idea, or feeling.

Three basic approaches were formed to explain how representation through language works i.e. reflective approach, the intentional approach, and constructionist approach. In the reflective approach, meaning was considered to embed in the object, person, idea or event in the real world. Language functions like a mirror reflecting its true meanings existed in the world. As for intentional approach, it was considered having a major flaw in a way that the language cannot be a private game. Because the language is used for communication, it needs to rely on shared codes and linguistic conventions. The third approach was called constructionist approach. This approach embraced the existence of the material world whose meanings are given by the social actors. The meanings are grounded on the conceptual system of their culture, linguistics, and other representational systems.

\section{Method}

\subsection{Research Instrument}

According to the study of Ashworth and Lucas (1998), phenomenology has been initiated from educational study. The aim of this qualitative approach primarily was to examine phenomena from the student's worldviews collected from various mental processes (e.g. perceiving, conceptualizing, apprehending, understanding and so on) which are overall referred to as 'experience'. Afterwards, phenomenology was developed further to explore of how students perceive key concepts and processes of academic disciplines. Ashworth and Lucas (2000) emphasized that the methodology was very influential for higher education research.

In order to acquire the student's opinions during the interview, Ashworth and Lucas (2000) proposed that the researcher needs to "bracket" or set aside his/her opinions and allow the student's own worldviews to emerge. They stated that some presuppositions should remain between the researcher and participants otherwise these conversation would be purposeless. The presuppositions were shared topic and verbalised in terms which both parties recognize as meaningful. They viewed that an unexpected result of phenomenographic research may be that the methodology sheds a new light on what composes a key concept and the nature of that concept.

In this study, the interview guidelines originated from literature review in a form of open-ended questions. A set of interview questions outline some significant points underpinned by the literature review. A pilot test was conducted before the data collection through interviewing. The question guideline was then slightly extended to make the questions more understandable for the interviewees. During the interviews, probing questions used were slightly varied from individual to individual.

\subsection{Participants and Data Collection}

The study has applied some parts of practical guidelines in conducting the phenomenographic research set out by Ashworth and Lucas (2000). The adapted criteria cover the stages of selection of participant, pre-interview, and conducting the interview. These practical guidelines adopted aim to minimize the issues of bracketing and allow registration of students' worldviews on the university uniform so far as possible.

The selection of participants aimed to acquire a wide range of experiences. A total of eight participants was of four males and four females from two Thai universities. Four students were from Kasetsart University, Kamphaeng Saen Campus (KU. KPS) and another four students were from Nakorn Pathom Rajabhat University (NPRU). In each university, four participants are drawn from two academic fields - education and tourism. One male student and one female student were selected in each field to provide data for the study. All participants aged 20-22 years old.

Prior to the interview, the participants have been informed of broad objectives of the study tentatively concerning the university uniform as phenomenon under investigation. The researcher proposed the definition of undergraduate uniform to the participants to create a common ground of understanding. The participants understood well that they could freely alter definitions and answer the questions as viewing proper.

In ensuring the participants' freedom of speech, the participants were informed about the anonymity to be used in the 
report, permission to skip any questions, and leaving the discussions anytime once they feel unease with the interview. The consent form from each participant was signed to acknowledge such agreements. Codes were assigned based on genders of male and female to conceal the identity of participants; for instance, M1 means the first male participant and F1 means the first female participants. The codes are applied to the whole group of participants.

Occasionally, the participants hesitated to answer the guideline questions due to the concern that what they think may not touch a chord with the researcher's expected answers. Being aware of higher power of researcher previously holding a lecturing position in the two universities, the researcher approached the participants with relaxing and humble gestures to create safe atmosphere for free discussions. The emphasis on a wide range of possible answers was given to the participants. The answers were derived based on the participants' interest. For some ambiguous answers, the participant were urged to give more explanations and examples.

The feelings of participants were continuously focused in transcription process. The majority of transcriptions contain wording of emotional expression such as proud, feel, respect, look, want, uncomfortable, and tight. The transcription of interviews are showed to support findings. The feelings of participant lead to the themes in findings.

\subsection{Data Analysis}

Thematic content analysis is used for analysis and interpretation of data in this study. Burnard (1991) suggested that the approach is suitable for phenomenology to analyze semi-structured, open-ended interviews with full transcription of the interviews recorded. The approach was viewed to focus on categorizing and codifying the transcription which aim at delivering a detailed and systematic analysis of the themes including issues raised in the recorded interviews. Thus, the themes were formed and linked to the interviews under a reasonable category system.

Data analysis of this study is elaborated grounded on Burnard (1991) as the following.

1. A table of content analysis was created comprising of three columns i.e. (a) order of question, (b) questions of subtheme and (c) its data, and findings.

2. Codes were opened through reading all of transcripts and underlying verbatim.

3. Verbatim were put in the column of findings. Verbatim which had similar sense or contents were grouped together in order to find subcategory.

4. Explanations were written based on verbatim and then headings were given to each group as subcategory to put scattering data into a story. Meanwhile, repetitions in the process of coding were examined and removed.

5. Subcategory conveying similar senses were grouped together to form category so as to see a larger picture.

6. Category and subcategory were examined to finalize all of the lists and ensure that the lists cover all perspectives related to the themes and subthemes. The researcher referred back to the original data many times during the process to adjust subtheme, category, and subcategory to make the findings reflect the phenomenon truthfully.

7. The researcher started writing descriptions of each theme, subtheme, and category to complete a section of findings.

\subsection{Validity and Reliability}

The fluid nature of qualitative research brings challenges to evaluation of its quality. In order to justify the value of qualitative research, Hammersley (as cited in Cutcliffe \& McKenna, 1999) proposed that its assessment criteria should be comparable to that of quantitative research. Shenton (2004) shared similar opinion and translated evaluating criteria to be practical for assessing qualitative research; these are credibility (in preference to internal validity), transferability (in preference to external validity/generalisability), dependability (in preference to reliability), and confirmability (in preference to objectivity).

To ensure credibility, phenomenology approach was adopted which is prevalently used in education science. The sense of familiarity with the institutions under the study was developed as the Thai researcher used to work as English lecturer of those two universities of NPRU and KU.KPS of seven months and one and a half years respectively. In terms of finding the participants, the university students who became participants were to a certain degree randomly selected to join the study, in the sense that the researchers did not know them well personally, except two participants of Hotel and Tourism Management Program of KU.KPS. Furthermore, probing questions are used to clarify some abstract concepts. As for transferability, the research on university uniform conducted in the context of Thai culture can be applied to the contexts of universities in developing countries elsewhere that are imposing uniform to their students at undergraduate level. Dependability can be acquired through the flexibility of phenomenology. The universities provided the academic platform which supported data collection, and participants were willing to give information and share their experiences. The pilot test was conducted before data collection. In achieving the confirmability, the researchers clarify preliminary theories that were not generated by the data. To reach confirmability, the sense of social facts was explored through 
interpreting experiences of participants. Personal opinions were put aside and data were analyzed according to experiences of participants through the interviews recorded. In data analysis, some definite preconceived categories were not used, instead the categories rather flow from the data.

\section{Findings and Interpretation}

Overall, the student uniforms in most universities are relatively similar. The dress code of all the uniforms is extremely formal and the rules are strict. The colors are normally only black and white. Women's dress code shows more variation for different occasions. Universities' signs and markers on tie and belt are an essential part of the dress code. All in all, gender differences are clearly accentuated, hence we can conclude that based on the dress code descriptions, it seems that the studied universities clearly demonstrate conservative ethos as regard for the norm set to their students' habitus and behavior.

Based on Bourdieu's theory of practice, power is unequally distributed among social actors (Navarro, 2006). A considerable number of scholars has concluded that uniform's function as a sort of capital constructs symbolic communication and underpins hierarchy (Aggleton and Whitty, 1985; Archer, Hollingworth \& Halsall 2007; Hertz, 2015; Horvat \& Antonio, 1999; Lovett, 2013; Michelman, 1997; Raby, 2005). These perceptions are similar to the research finding: the uniform of university students in Thailand's context produces symbolic communication and sustains hierarchy.

Table 1 Themes and subthemes regarding the student uniforms at Thai universities

\begin{tabular}{ll}
\hline Themes & Subthemes \\
\hline The uniform as the representation of power relations & Symbolic communication \\
& Hierarchical empowerment \\
The influence of the dress code on student's personal development & Illusion of uniformity \\
& Suppression of individuality \\
& Limiting gender acceptance \\
& Not promoting life goals \\
\hline
\end{tabular}

\subsection{The Uniform as the Representation of Power Relations}

In terms of power relations, uniform functions as symbolic communication and plays an important role in hierarchical empowerment.

\section{Symbolic communication}

The uniform provides symbolic communication among different groups of social actors inside and outside the university. The symbolic communication consists of two categories namely social class and economic capital i.e. prosperity. In terms of social class, the uniform is a cultural representation of a certain group of people belonging together. Hence the students have positive views toward the university uniform because it is a symbol of their group and the unity shows that they are members of a certain university. 'The student uniforms make me feel as a part of university.' (F1) The uniform functions as a social class marker and operates as a symbol of cultural representation. In generating affirmation of social class, the uniform signifies uniformity in the form of student membership of their universities. Several researchers showed a perception that dress code represents membership in a social setting which chimes with the study (Craik, 2003; Roach-Higgins, Eicher, \& Johnson, 1995). Wearing the uniform also means showing obedience to the rules set by the superiors and thus signifies the respect of inferiors to them. 'Wearing the student uniform shows respect to senior, lecturer, and institution.' (M1) An affirmation of Roach-Higgins, Eicher, and Johnson (1995) that dress announced communicating identities conforms to the finding that wearing the uniform to attend classes can imply humble identity of the students in front of the lecturers and senior students. Garber (1997) proposed the same view that demanding a certain dress code in a school can be interpreted as acceptance of one's position in the hierarchy as the students accept the rules of dress code initiated by a principal. The theory of cultural representation by Hall (1997) is used to explain that uniform works similarly to a language in this case. The scope of language here is not restricted to communicative forms of written or spoken, but extended to a roughly similar interpretation of visual image among Thai people. The research on wearing the uniform relies on constructionist approach. Despite the fact that uniform is merely an object, the lecturers holding authority in the universities as dominant actors give certain meaning to this practice.

A function of uniform as a symbol operates not only inside but even in spaces outside the university. As for prosperity, the uniform becomes a symbolic representation of successful study life and higher value of big universities among the students who pass a national entrance examination. The logo of famous university makes the students proud of being its member. 'I was very proud because I got admission at KU. It is top-three university of the country....I wore KU token to several places' (F4) On the other hand, the students failing entrance examination feel uncomfortable when seeing those 
who pass the examinations. They made comparison and then became disheartened. 'Seeing their uniforms attached with logo of big universities, I feel that they have higher value than me. They look more admirable because they got admitted.'(M2). In Thailand's context, giving high value to the top universities is not only a norm among students and employers, parents also have this conviction. The study of Roach-Higgins, Eicher, and Johnson (1995) also supported the idea that dress announces social position of the wearers which leads to social interaction with wearer and observer within a particular interaction situation. The uniform, therefore, brings prejudgment of viewers toward the wearers without personal contacts and emphasizes classification among students on daily basis. This statement corresponds to Hertz (2015) mentioning that uniform embodies different meanings for different audiences.

\section{Hierarchical empowerment}

The uniform exerts strong influence on hierarchical empowerment inside the university through offering a tool of lecturers and tool of senior students for controlling the newcomers. The uniform offers arbitrary power to the lecturer. 'Before teaching, some lecturers would call names and ask the students to stand up. If we dress improperly, our scores would be deducted.' (M4) This atmosphere leads to lecturer's over-empowerment. The lecturers can decide how far they want to take the strict rules with the uniform. 'At present, wearing pleated skirt is allowed or not depends on lecturer of the subject' (M1) By strictly imposing dress codes, the lecturer can create fear among students because they implement harsh punishments. 'No one ever dares to take any move... If we don't bring name tags, he will not allow us to enter into the classroom.' (M2) The lecturers are usually stricter to first-year students about the uniform, compared with senior students because the newcomers are not familiar to university system. 'However, the lecturers would focus on the first year students because they just entered into the university.' (F1) The first priority given to embedding a passive mindset to students through strict dress codes can result in weak academic performance. 'They focus on good image, but view academic performance and capability less important.' (M1) The strict uniform rule undermines the courage of raising questions. The students learn that raising questions and acting against the rules would put them into troubles instead of receiving consideration or finding resolutions that lecturers and students would both be satisfied with. 'I used to raise this question to myself many times, but I cannot do anything. Then, I stop asking question. Following their orders are easier.' (M2) Hertz (2015) mentioned that uniform is aimed for control of a group hierarchy. In the study of nurse uniform (Pearson, Baker, Walsh, \& Fitzgerald, 2001), its findings interestingly revealed that the real power is represented by moving out of uniform. That is, people at the very top position of hierarchy do not wear the uniform. Such finding aligns with the practice of Thai lecturers that they are on the top of hierarchy, hence they do not wear the uniform. Lawson (2006) argued that empowerment can be initiated by allowing people to voice out their opinions about their new dress code. Her opinion resonates with the findings that allowing the lecturers to set up and implement rules and regulations about the uniform without listening to the students' opinions results in high empowerment to the lecturers.

The senior students from year two to four usually participate in the initiations or Junior Greeting Activities. Wearing improper uniform is normally used as an excuse to punish first-year students. 'We punished the juniors every day for wearing improper uniform. We ordered them to run around the Program's building.' (M2) Every generation of first-year students receives punishment because of 'neglecting' the dress code. Once these first-year students become senior students, they implement such practice to the newcomers as well. 'The rules of Junior Greeting are changed. The senior students who used to face bad Junior Greeting do not feel good because they had worse experiences in their years while the junior students had softer activities.' (MI) Some seniors never engage in any activities of the universities. Nonetheless, they enjoy extending their freedom of expression while limiting junior's freedom by using privilege of seniority. They make a claim for improper uniform in order to justify punishment. 'I witnessed some aggressive classmates who complained the junior students about dying hair and wearing improper uniform, but they and I also changed our hair colors and wore improper uniforms.' (M4) The senior students using uniform as a tool to control junior students is supported by an existing culture of hierarchy in the universities. Olaoye (2013) notified that dress code promotes a culture of seniority aligning with the research finding. In Thailand's context, the senior students are temporarily over empowered and then they create fear among first-year students of being punished with a claim for improper uniform. Their hierarchical status maintained by violent reactions is transmitted from generation to generation and results in a certain degree of violation of individual freedom of first-year students. All in all, by maintaining the uniform rules and regulations, the lecturers and senior students can sustain their power and status quo.

\subsection{The Influence of the Dress Code on Student's Personal Development}

In relation to personal development, the uniform involves with illusion of uniformity, suppression of individuality, limiting gender acceptance, and does not promote life goals.

\section{Illusion of uniformity}

The illusion of uniformity due to the strict dress code comprises behavioral issues and may create false perceptions toward 
disciplinary matters and improvement of knowledge and professional skills. Behavioral issues due to the dress code deal with classroom attendance and submission of assignment. The students viewed that punctuality depends on personal conscience and how well a person can manage his or her time. 'The student uniform is not related to attending classroom on time. It depends on the individual behaviour.' (M3) and 'The male students in my Program do not pay attention in submitting assignments and they reach the classroom late every day although they wear proper uniform.' (M2) The uniform does not promote knowledge acquisition. The uniform only represents rules that the student needs to follow to avoid unnecessary punishment. 'Isaac Newton does not wear the uniform when he discovers physics rules.' (M3) Obviously, the practice of wearing uniform gave an impression of creating uniformity (Chira, 2016; Meadmore and Symes, 1997). However, Hertz (2015) argued that uniform does not create a string sense of uniformity among wearers. Expecting uniformity of students due to the strict dress code is more like an illusion. On the other hand, Craik (2003) found that uniform signifies quality of disciplines and reliability and inculcates new habits valued in the society. Further, Johnson, Lennon, and Rudd (2014) emphasized that the clothes holding symbolic meaning affect the wearer's behaviors. Nonetheless, the research findings reveal that the uniform cannot embed positive behaviors concerning punctuality in classroom attendance and responsibility of submitting academic assignments. Lovett (2013) presented that the impressions of peers' academic ability and chances for school success are grounded on the outfit of students. On the contrary, the research findings in the university context inform that proper uniforms do not as such promote knowledge acquisition.

\section{Suppression of individuality}

The uniform is viewed as suppression of individuality because of institutionalized identities, and discomfort. In order to feel more relaxing and personal, and to prevent social blames from making some mistakes, the students are likely to take off the uniform before doing any personal activities. '...sometimes I have to manage urgent personal matters. I need to go home and change the dress.' (M1) The uniform causes physical discomfort and becomes a barrier to personal actions. Due to the uniform's garment and fixed pattern, it is not flexible, soft, nor comfortable to wear and it does not well ventilate the heat. 'The shirt does not allow my arms to move freely. It is not because I'm fat. When I was slim in the first year, I also feel this tightness.' (F4) The suppressive influence of uniform on individuality was pointed out by Adomaitis and Johnson (2005) as well as by Hertz (2015), whose notions aligned with the research finding. In Thailand's context, wearing the uniform suppresses individuality by exerting institutionalized identities, and creates strong sense of discomfort to some students. The study of Hansen (2004) mentioning that cultural clothes construct individual identity was congruent with the study outcome, which discloses that the uniform retains and enforces institutionalized identities. In Thailand, the uniform labels identity through representing image or identity of university over the student's body. In relation to discomfort, Adomaitis and Johnson (2005) found that dress code identifies the status of the wearer. Thai students often feel uncomfortable while wearing the uniform and cannot take any actions in their own styles due to the concern over the institutional image. More importantly, the formal uniform can bring physical discomfort and reserve the personal behaviors of Thai university students.

\section{Limiting gender acceptance}

In relation to gender issues, the uniform is problematic because it undermines self-reliance upon physical movement and transportation of women. Also, the uniform creates sexual anxiety based on its conservative concept. The uniform becomes problematic because it demotes self-reliance of female students and makes them more prone to accidents. 'Wearing an A-line skirt causes difficulty when I need to sit on motorcycle. I have to sit by keeping my legs on one side, not in a normal riding post.' (F1) In relation to sexual anxiety, the uniform maintains conservative concept of gender. The uniform only allows males and females to appear in the formal education atmosphere and ignore LGBTI (lesbian, gay, bisexual, transgender, and intersexual) people. 'I want to wear clothes like females. .....The Program doesn't allow me to have long hair while other programs allow this. I want to do like that, but I can 't. I want to change....'(M2) Gender under the uniform could not be easily masked (Hertz, 2015). Zalesne (2007) further explained that uniform causes gender identity discrimination because the dress code is normatively designed for male and female. Uniform values males as the dominant and competent gender while degrading females to their conventional domestic, sexual, and reproductive roles. Uniform is harmful to women and punishes those who deviate their gender roles from the gender-based stereotype. Perception of Zalesne (2007) about wearing the uniform concerning gender issues corresponds to the finding that uniforms become problematic to women and can cause sexual anxiety. In order to avoid punishment, the students need to adapt themselves to comply with rules and regulations of dress code whatever their true gender identity are.

\section{Not promoting life goals}

Concerning life goals, the uniform creates unclear vision because it does not actually signify future profession of students as it only promotes similarities, that is, uniformity. In addition, it may repress success in studies as it promotes neither academic performance nor professional skills. The uniform of specific professions such hotel and tourism programs makes the students proud because of people's admiration. Some people misunderstand that they work for an 
airline. 'Some do not think that this is a hotel suit, but they think it is a suit for flight attendant. I am proud with this hotel suit.' (M2) The uniform promotes similarities among students, rather than differences. 'The uniform does not support difference....'(F3)

In terms of repressing success, the uniform does not promote academic performance nor professional skills and it reduces learning motivation. Good academic performance relies on individual's attention. 'The uniform just reminds us that we are studying. The academic performance, however, depends on individual eagerness.' (M3) The uniform does not promote professional skills. The students view that professional skills are fundamentally promoted by determination and work experiences. 'The uniform does not improve my teaching skills. The quality of teaching depends on intentions and experiences.' (F1) In order to study well, the students want to feel the most comfortable with their body movement. 'The uniform does not motivate learning. I want to learn more when I wear casual clothes. The uniform makes me uncomfortable and tight. I don't want to do anything.' (F4) Setting up life goals is very important for undergraduate students because it was used as an intervention to improve academic performance and treatment for students on academic probation (Morisano, Hirsh, Peterson, Pihl, \& Shore, 2010). School uniforms are investigated whether they can promote academic performance of students and the results showed that they are not related to academic performance based on student's perspectives (DaCosta, 2006; Firmin, Smith \& Perry, 2006). These studies are consistent with the finding that the dress code only offers a blurred vision of some desirable careers in hotel and tourism industry. It cannot guarantee their success after graduation because the uniform cannot as such promote neither academic performance nor professional skills. A perception of Raby (2005) considering that uniform promotes similarity corresponds to the outcome of study. In addition, the uniform often reduces learning motivation in Thailand's context.

\section{Conclusion}

In this study, the influences of uniform regarding power relations and students' personal development were explored. Theoretical framework adopted to unmask the foundations of phenomenon are Bourdieu's theories composed of capital and habitus, and Hall's cultural representation. Phenomenology was used to inspect experiences of the undergraduate students wearing the uniform to illustrate the reality inductively. Through the analysis, it was found that the student uniform clearly functions on symbolic level. Therefore, it plays an important part in power relations by constructing hierarchy in Thailand's universities and entire society. In the university sphere, the top-down hierarchy consists of lecturers, senior students, and first-year students. In the social setting, the students wearing uniform of top universities consist of the upper class while the others are members of the lower class. As for personal development, the uniform neither implants qualifications of punctuality nor responsibility among the students. Moreover, the uniform promotes neither academic performance nor professional skills of students as widely claimed, but it rather creates unnecessary stress to them. The study discloses an unexpected viewpoint in educational practice, that is, a rigid practice of uniform is likely to imply that the universities prioritize perfection of dress code over academic performance.

This work fulfils the academic gap of the uniform research on undergraduate level. The results of this study are to great extent generalizable and useful to encourage better practices in the university and society, particularly in Thailand's context. In this regard, the practice of uniform should be cautiously considered which revolves around constructive learning environment in the university and reduction of biases among people in the society. Also, there are several research perspectives concerning the dress codes and uniforms which remain to be explored such as its influence on democratic practices and individuals' critical thinking.

\section{Limitations}

Translating texts from Thai into English brings about technical weakness due to some language gaps and selections of translated words which may not represent exact thoughts or perceptions of participants. As a result, some unintentional biases on language may happen due to personal selection of word choices.

\section{Acknowledgements}

No funding from any institution provided to conduct this research. The study was taken from master's thesis in education of University of Oulu (Finland) dated April 2017 of Ms. Sasanun Bunyawanich. Docent Professor Maria-Liisa Järvelä is the advisor to this thesis. Mr. Abdul Ghaffar provides a great support in shaping the thesis from the beginning to the end.

\section{References}

Adomaitis, A. D., \& Johnson, K. K. (2005). Casual versus formal uniforms: Flight attendants' self-perceptions and perceived appraisals by others. Clothing and Textiles Research Journal, 23(2), 88-101. https://doi.org/10.1177/0887302X0502300203

Aggleton, P. J., \& Whitty, G. (1985). Rebels without a cause? Socialization and subcultural style among the children of the new middle classes. Sociology of Education, 60-72. https://doi.org/10.2307/2112541 
Anheier, H. K., Gerhards, J., \& Romo, F. P. (1995). Forms of capital and social structure in cultural fields: Examining bourdieu's social topography. American Journal of Sociology, 859-903. https://doi.org/10.1086/230603

Archer, L., Hollingworth, S., \& Halsall, A. (2007). University's not for me — I'm a Nike person': Urban, working-class young people's negotiations of Style', identity and educational engagement. Sociology, 4l(2), 219-237. https://doi.org/10.1177/0038038507074798

Ashworth, P., \& Lucas, U. (1998). What is the 'world' of phenomenography? Scandinavian Journal of Educational Research, 42(4), 415-431. https://doi.org/10.1080/0031383980420407

Ashworth, P., \& Lucas, U. (2000). Achieving empathy and engagement: A practical approach to the design, conduct and reporting of phenomenographic research. Studies in Higher Education, 25(3), 295-308. https://doi.org/10.1080/713696153

Bourdieu, P. (1984). Distinction: A social critique of the judgment of taste Harvard University Press.

Bovornsiri, V., \& Fry, G. (1991). Higher education and Thai development: Past successes and future challenges. Higher Education Policy, 4(2), 30-35.https://doi.org/10.1057/hep.1991.25

Bunyavejchewin, P. (2010). Constructing the 'Red' Otherness: The role and implications of Thainess on polarised politics. Austrian Journal of South-East Asian Studies, 3(2), 241-248.

Burnard, P. (1991). A method of analysing interview transcripts in qualitative research. Nurse Education Today, 11(6), 461-466. https://doi.org/10.1016/0260-6917(91)90009-Y

Chira, S. C. (2016). Globalisation of fashion, social patterns and loss of personal identity. Textile Science and Economy, 85-104.

Chulalongkorn University's student uniform. Retrieved from http://www.chula.ac.th/about/symbol/symbol_abbrv

Craik, J. (2003). The cultural politics of the uniform. Fashion Theory, 7(2), 127-147. https://doi.org/10.2752/136270403778052140

Craik, J. (2005). Uniforms exposed. Uniformierungen in Bewegung, 37. https://doi.org/10.2752/9781847881212

Cutcliffe, J. R., \& McKenna, H. P. (1999). Establishing the credibility of qualitative research findings: The plot thickens. Journal of Advanced Nursing, 30(2), 374-380. https://doi.org/10.1046/j.1365-2648.1999.01090.x

DaCosta, K. (2006). Dress code blues: An exploration of urban students' reactions to a public high school uniform policy. The Journal of Negro Education, 49-59.

DeMitchell, T. A., Fossey, R., \& Cobb, C. (2000). Dress codes in the public schools: Principals, policies, and precepts. $J L \& E d u c ., 29,31$.

Fakjamroon, S. (2005). Practices of Wai Kru. Retrieved from http://www.east.spu.ac.th/activities48/pr/pr01.html

Garber, M. B. (1997). Vested interests: Cross-dressing and cultural anxiety Psychology Press.

Grubbs, S. J. (2012). An investigation into a Thai university initiation. Asia Pacific Education Review, 13(1), 39-46. https://doi.org/10.1007/s12564-011-9172-y

Hall, S. (1997). Representation: Cultural representations and signifying practices Sage.

Hansen, K. T. (2004). The world in dress: Anthropological perspectives on clothing, fashion, and culture. Annu. Rev. Anthropol., 33, 369-392. https://doi.org/10.1146/annurev.anthro.33.070203.143805

Hertz, C. (2015). The uniform: As material, as symbol, as negotiated object. Midwestern Folklore,

Horvat, E. M., \& Antonio, A. L. (1999). "Hey, those shoes are out of uniform": African American girls in an elite high school and the importance of habitus. Anthropology \& Education Quarterly, 30(3), 317-342. https://doi.org/10.1525/aeq.1999.30.3.317

Johnson, K., Lennon, S. J., \& Rudd, N. (2014). Dress, body and self: Research in the social psychology of dress. Fashion and Textiles, 1(1), 1-20. https://doi.org/10.1186/s40691-014-0020-7

Joseph, N., \& Alex, N. (1972). The uniform: A sociological perspective. American Journal of Sociology, 719-730. https://doi.org/10.1086/225197

Kitkerdsaeng, J. (2011). Wai Kru tradition. Retrieved from arit.rmutp.ac.th/wp-content/uploads/2011/06/6.1Waikru.pdf

Lawson, K. (2006). Four keys to employee empowerment. Article http://www.growinggreatness.com/gg_articles/Empowering_Employees.pdf

Liamputtong, P. (2014). Contemporary socio-cultural and political perspectives in Thailand Springer. 
Lovett, T. W. (2013). What the blazers? The effect of cultural symbols on class identity and learning outcomes. The Journal of Educational Enquiry, 12(1), 1-14.

Meadmore, D., \& Symes, C. (1997). Keeping up appearances: Uniform policy for school diversity? British Journal of Educational Studies, 45(2), 174-186. https://doi.org/10.1111/1467-8527.00044

Mezey, S. G. (1975). Political socialization and participation among university students in Thailand. Asian Survey, 15(6), 499-509. https://doi.org/10.1525/as.1975.15.6.01p0083b

Michelman, S. O. (1997). Changing old habits: Dress of women religious and its relationship to personal and social identity. Sociological Inquiry, 67(3), 350-363. https://doi.org/10.1111/j.1475-682X.1997.tb01101.x

Morisano, D., Hirsh, J. B., Peterson, J. B., Pihl, R. O., \& Shore, B. M. (2010). Setting, elaborating, and reflecting on personal goals improves academic performance. Journal of Applied Psychology, 95(2), 255-264. https://doi.org/10.1037/a0018478

Nainapat, P. (2016). No yelling, no disheartening, no command - New junior initiation of Kasetsart University. Retrieved from http://thematter.co/pulse/answer-froffm-kusc/5852

Navarro, Z. (2006). In search of a cultural interpretation of power: The contribution of Pierre Bourdieu. IDS Bulletin, 37(6), 11-22. https://doi.org/10.1111/j.1759-5436.2006.tb00319.x

Olaoye, A. (2013). Nigerian dress culture: A linguistic and anthropological communication tool. Journal of ELT and Applied Linguistics (JELTAL), 1(2), 32-42.

Pearson, A., Baker, H., Walsh, K., \& Fitzgerald, M. (2001). Contemporary nurses' uniforms-history and traditions. Journal of Nursing Management, 9(3), 147-152. https://doi.org/10.1046/j.1365-2834.2001.00207.x

Raby, R. (2005). Polite, well-dressed and on time: Secondary school conduct codes and the production of docile citizens. The Canadian Review of Sociology, 42(1), 71-91. https://doi.org/10.1111/j.1755-618X.2005.tb00791.x

Renard, R. D. (2006). Creating the other requires defining Thainess against which the other can exist: early-twentieth century definitions. Southeast Asian Studies, 44(3), 295-320. https://doi.org/10.20495/tak.44.3_295

Rhein, D. (2016). Westernization and the Thai higher education system: Past and present. Journal of Educational Administration and History, 1-14.

Roach-Higgins, M. E., Eicher, J. B., \& Johnson, K. K. (1995). Dress and identity Fairchild Publications New York, 7-18.

Sablan, J. R., \& Tierney, W. G. (2014). The changing nature of cultural capital. Higher education: Handbook of theory and research, Springer, 153-188. https://doi.org/10.1007/978-94-017-8005-6_4

Sattayanurak, S. (2008). The construction of mainstream thought on "Thainess" and the "truth" constructed by "Thainess". Chiang Mai University. Retrieved from http://www.thaimissions.info/gsdl/collect/thaimiss/index/assoc/HASH0182/3bba5980.dir/doc.pdf

Shenton, A. K. (2004). Strategies for ensuring trustworthiness in qualitative research projects. Education for Information, 22(2), 63-75. https://doi.org/10.3233/EFI-2004-22201

Siisiäinen, M. (2003). Two concepts of social capital: Bourdieu vs. Putnam. International Journal of Contemporary Sociology, 40(2), 183-204.

Sooksai, C. (2013). Discourse on student uniform. [Discourse on Student Uniform], November 14, 2015. Retrieved from http://www.siamintelligence.com/discourse-on-student-uniform

Walther, M. (2014). Bourdieu's theory of practice as theoretical framework. Repatriation to France and Germany, Springer, 7-23. https://doi.org/10.1007/978-3-658-05700-8_2

Zalesne, D. (2007). Lessons from equal opportunity harasser doctrine: Challenging sex-specific appearance and dress code. Duke J.Gender L. \& Pol'y, 14, 535-560.

\section{Copyrights}

Copyright for this article is retained by the author(s), with first publication rights granted to the journal.

This is an open-access article distributed under the terms and conditions of the Creative Commons Attribution license which permits unrestricted use, distribution, and reproduction in any medium, provided the original work is properly cited. 